\title{
Severe hypoglycaemia caused by raised insulin-like growth factor II in disseminated breast cancer
}

\author{
E M Bessell, C Selby, I O Ellis
}

\begin{abstract}
A 60 year old woman with disseminated ductal carcinoma of the breast developed non-islet cell tumour induced hypoglycaemia (NICTH). The concentrations of the two insulin-like growth factors, IGF-I and IGF-II, were < 2 nmol/1 and $94.1 \mathrm{nmol} / 1$, respectively. The IGF-II to IGF-I ratio was $>47$ (normal $<10)$. Insulin $(<3 \mathrm{mu} / 1)$ and $C$ peptide $(<100$ pmol/1) were both undetectable.

(f Clin Pathol 1999;52:780-781)
\end{abstract}

Keywords: breast carcinoma; insulin-like growth factor; hypoglycaemia

Hypoglycaemia is a well recognised albeit rare complication of benign and malignant mesenchymal tumours, which have been mostly bulky and slow growing. ${ }^{1}$ Hypoglycaemia associated with a mediastinal fibrosarcoma was first reported in $1930 .^{2}$ Since then there have been several reports in a variety of tumours including carcinomas. ${ }^{1}$ Patients who have presented with hypoglycaemia and been found to have an operable sarcoma or benign mesenchymal tumour have been rendered normoglycaemic by surgical resection of the tumour, but this is not possible in those with metastatic carcinoma. Hypoglycaemia associated with those tumours differs from that caused by insulinomas in that during the episodes of hypoglycaemia plasma insulin and $\mathrm{C}$ peptide concentrations are low; it has thus been termed non-islet cell tumour induced hypoglycaemia (NICTH).

In earlier reports the hypoglycaemia was thought to be caused by increased uptake of glucose by bulky tumours, ${ }^{1}$ but with the development of reliable assays for insulin-like growth factors (IGF) it is now thought probable that most cases result from an increase in IGF-II relative to IGF-I. ${ }^{3}$ IGF-II is expressed both in breast cancer cells and stromal cells in breast cancer biopsy specimens. ${ }^{4}$ Almost all breast cancer cell lines and fresh breast cancer biopsies have receptors for IGF-I, IGF-II, and insulin. ${ }^{5}$ It has been proposed that the IGF-I and IGF-II secreted by stromal cells present in malignant breast tumours have a regulatory role on breast cancer cells through paracrine pathways. ${ }^{5}$ In spite of this, an increased IGF-II to IGF-I ratio leading to hypoglycaemia has not previously been reported in patients with breast cancer.

Case history

A 45 year old woman presented in November 1981 with a $4 \mathrm{~cm}$ (stage T2) grade 3 ductal carcinoma of the right breast with involved axillary nodes. She was treated by simple mastectomy, axillary lymph node sampling, and postoperative radiotherapy without adjuvant hormone treatment or chemotherapy. In September 1986 she developed small subcutaneous/cutaneous nodules, confirmed by biopsy to be recurrent ductal carcinoma, and was treated with tamoxifen and subsequently with megestrol acetate. In December 1994 she developed bony metastases and was treated with palliative radiotherapy and aminoglutethimide and hydrocortisone, and subsequently with chemotherapy (cyclophosphamide, methotrexate, and 5-fluorouracil).

In September 1996 she complained of feeling cold and clammy between 4 am and 5 am. She was admitted for observation overnight but there were no further attacks for 10 days. She was admitted again drowsy and hypothermic $\left(34.5^{\circ} \mathrm{C}\right)$ with a plasma glucose of $1.1 \mathrm{mmol} / 1$ (normal 3.9-6.0), free thyroxine $10.2 \mathrm{pmol} / 1$ (normal 10.0-28.0), thyroid stimulating hormone $6.9 \mathrm{mu} / 1$ (normal 0.153.2), and cortisol $594 \mathrm{nmol} / \mathrm{l}$ (normal 280700). Three days later the serum IGF-I and IGF-II were $<2 \mathrm{nmol} / 1$ and $94.1 \mathrm{nmol} / 1$, respectively, with an IGF-II to IGF-I ratio of $>47$ (normal < 10). Insulin $(<3 \mathrm{mu} / \mathrm{l})$ and C-peptide $(<100 \mathrm{pmol} / \mathrm{l})$ were both undetectable. These measurements were made when the patient was hypoglycaemic (glucose 2.0 $\mathrm{mmol} / \mathrm{l}$ ) but receiving $10 \%$ dextrose infusion. The blood glucose was eventually maintained within the normal range with $10 \%$ dextrose $(125 \mathrm{ml} / \mathrm{h})$ and triiodothyronine was given intravenously ( $20 \mu \mathrm{g}$ twice daily). There was no improvement in her conscious level and she died seven days later. No necropsy was carried out. Her husband had non-insulin-dependent diabetes and was receiving glibenclamide. None of his tablets had been taken by the patient.

On histological review of slides from biopsies in 1981,1986 , and 1989, the breast carcinoma was found to be a primary grade 3 adenocarcinoma of invasive micropapillary type (fig 1). The tumour expressed a neuroendocrine phenotype showing positivity with CD56, neurone specific enolase, chromogranin, and synaptophysin. Positive immunocytochemical staining was also observed (fig 1) with a commercially available monoclonal antibody reactive to IGF-I and IGF-II (Upstate Biotechnology, New York, USA). 


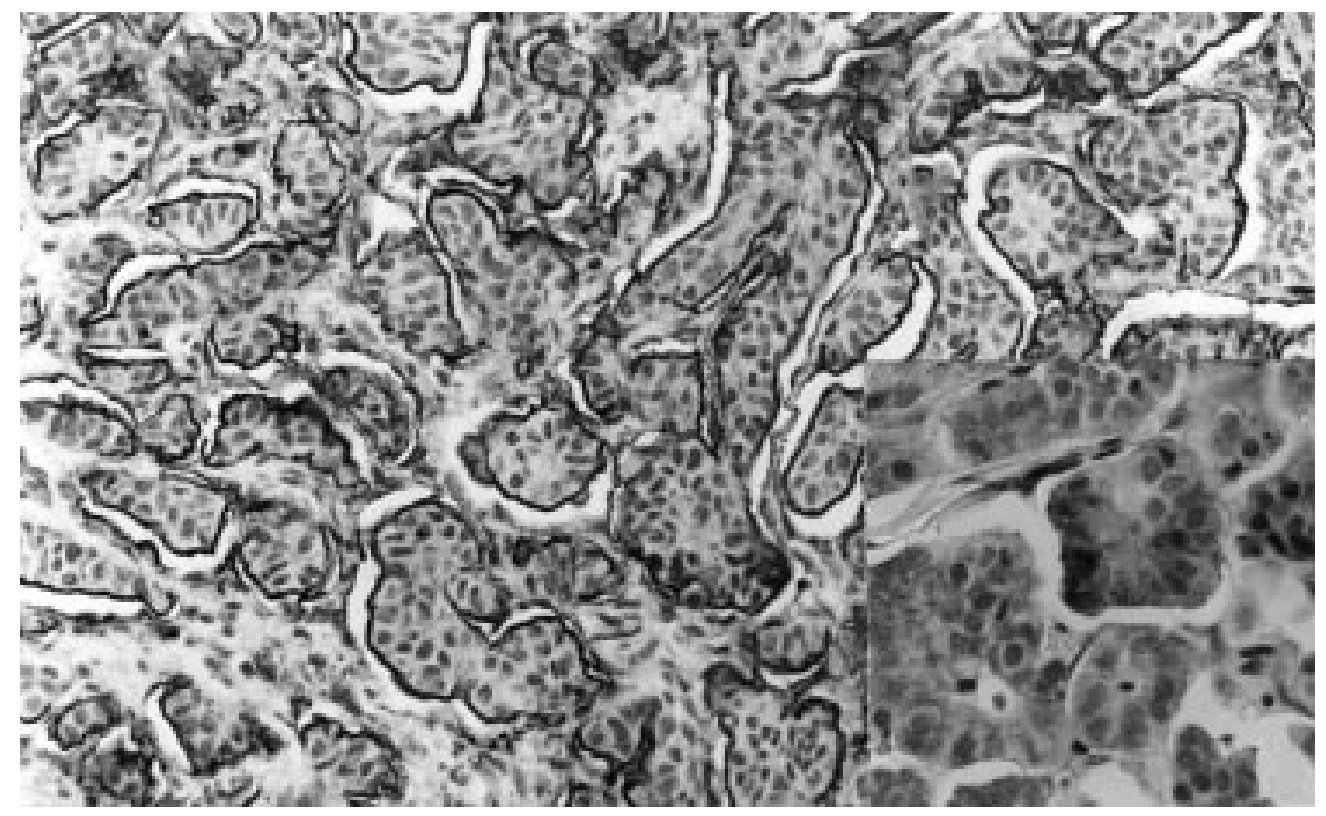

Figure 1 A photomicrograph of the tumour. Reversed polarity of the tumour cells, typical of invasive micropapillary type, is clearly demonstrated by immunocytochemical staining for MUC 1 (EMA) where positivity is seen as a peripheral rim of staining around each tumour cell island. The inset photomicrograph show positive granular cytoplasmic staining of some tumour cells with the insulin-like growth factor (IGF) monoclonal antibody.

\section{Discussion}

Hypoglycaemia caused by raised concentrations of IGF-II secreted by tumours is called non-islet cell tumour induced hypoglycaemia (NICTH). ${ }^{3}$ IGF-I (70 residues, MW 7649) and IGF-II (67 residues, MW 7645) are single chain peptides with approximately $70 \%$ and $50 \%$ sequence homology with pro-insulin, respectively. ${ }^{5}$ Both IGF-I and IGF-II are partial insulin agonists but IGF-II is normally bound to insulin-like growth factor binding proteins such as IGF BP-3. IGF-I is a regulator of growth, especially in mesenchymal tissues such as bone or cartilage, and IGFs have been shown to be tumour growth factors. ${ }^{5}$ A reduction in IGF BP-3 leads to increased free IGFII, and a reduction in growth hormone by negative feedback impairs the hepatic response to hypoglycaemia and suppressed IGF-I levels. ${ }^{6}$ The diagnosis of NICTH is therefore made by demonstrating low insulin/C-peptide levels together with an inappropriate increase in the ratio of IGF-II to IGF-I. Hypoglycaemia may not be recognised in patients with advanced malignancy unless the classic symptoms of sweating, faintness, and confusion occur. The breast carcinoma in this case report was a grade 3 adenocarcinoma of micropapillary type which stained with an IGF-I/IGF-II antibody. This subtype is a rare recently described type of breast carcinoma ${ }^{7}$ showing some morphological similarity to mucinous carcinoma, ${ }^{8}$ which also has reverse cell polarity and an association with neuroendocrine differentiation. We are not aware of any previous reports of neuroendocrine differentiation in invasive micropapillary carcinoma of the breast. Tumours with a growth pattern resembling carcinoid tumour are exceptionally rare and of questionable existence in the breast. ${ }^{9}$
However, neuroendocrine differentiation is observed in up to $25 \%$ of invasive adenocarcinomas (more commonly in the mucinous subtype). Invasive micropapillary carcinoma is usually associated with vascular invasion and short survival ${ }^{10}$ but in the case reported the patient lived for 15 years from diagnosis.

Surgical resection is not a treatment option when metastatic disease is present, and medical management is usually limited to glucose infusion as in this case. If the diagnosis of NICTH is made, administration of growth hormone and corticosteroids is often helpful in relieving the hypoglycaemia. ${ }^{6}$ Growth hormone levels are often low and corticosteroids stimulate gluconeogenesis and glycogenolysis.

We thank Dr D Teale from St Luke's Hospital in Guildford, Surrey, UK for performing the IGF assays.

1 Daughaday WH. Hypoglycaemia in patients with non-islet cell tumours. Endocrinol Metab Clin North Am 1989;18:91 101.

2 Doege KW Fibrosarcoma of the mediastinum. Ann Surg 1930;92:955-60

3 Teale JD, Marks V. Inappropriately elevated plasma insulinlike growth factor II in relation to suppressed insulin-like growth factor I in the diagnosis of non-islet cell tumour hypoglycaemia. Clin Endocrinol 1990;33:87-98.

4 Toropainen EM, Lipponen PK, Syrjannen KJ. Expression of insulin-like growth factor II in female breast cancer as related to established prognostic factors and long term related to established prognostic factors and
prognosis. Anticancer Res 1995;15:2669-74.

5 Macaulay VM. Insulin-like growth factors. Br f Cancer 1992;65:311-20.

6 Teale JD, Blum WF, Marks V. Alleviation of non-islet cell Teale JD, Blum WF, Marks V. Alleviation of non-islet cell
tumour hypoglycaemia by growth hormone therapy is associated with changes in IGF binding protein-3. Ann Clin Biochem 1992;29:314-23.

7 Siriaunkgul S, Tarassoli FA. Invasive micropapillary carcinoma of the breast. Mod Pathol 1993;6:660-2.

8 Elston CW, Ellis IO. The breast. Systemic pathology, 3rd ed, vol 13. Edinburgh: Churchill Livingstone, 1998:315.

9 Rosen PP. Rosen's breast pathology. Philadelphia: LippincottRaven, 1996

10 Luna-More S, Gonzalez B, Acedo C, et al. Invasive micropapillary carcinoma of the breast. A new special type of invasive mammary carcinoma. Pathol Res Pract 1994; 190:668-74. 